05;06

\title{
Кластеры Mn в нанопористом углероде: магнитные свойства
}

\author{
() А.М. Данишевский ${ }^{1}$, Н.В. Шаренкова ${ }^{1}$, Б.Д. Шанина ${ }^{2}$, С.К. Гордеев ${ }^{3}$ \\ ${ }^{1}$ Физико-технический институт им. А.Ф. Иофрфе РАН, Санкт-Петербург, Россия \\ ${ }^{2}$ Институт полупроводников НАН Украины, \\ Киев, Украина \\ ${ }^{3}$ Центральный научно-исследовательский институт материалов, \\ Санкт-Петербург, Россия \\ E-mail: Alex.D@mail.ioffe.ru
}

Поступило в Редакцию 26 декабря 2018 г.

В окончательной редакции 15 февраля 2019 г.

Принято к публикации 18 февраля 2019 г.

Представлен метод введения кластеров Мn в нанопористый углерод. Продемонстрированы полученные магнитные свойства таких композитных образцов в динамике их развития во времени.

DOI: 10.21883/PJTF.2019.09.47714.17658

Введение кластеров переходных металлов (Ni, Co, Pd) в поры нанопористого углерода (НПУ) приводит к существенным изменениям электрических и магнитных свойств получаемых таким образом композиционных образцов $[1,2]$. Условия экспериментов в $[1,2]$ исключали возможность образования карбидов металлов, и основным воздействием являлось адсорбционное взаимодействие электронных термов углерода и металла, эффективность которого обусловливалась малостью размеров микропор углеродного остова $(0.8-2 \mathrm{~nm})$ и их большой удельной поверхностью $\left(\sim 1500 \mathrm{~m}^{2} / \mathrm{g}\right)$.

В настоящей работе проведено исследование возможностей введения в НПУ кластеров марганца и изучены магнитные свойства композита.

Марганец имеет четыре типа кристаллических структур, но до $700^{\circ} \mathrm{C}$ он находится в стабильной альфа-фазе (объемно центрированная решетка, постоянная решетки $0.8918 \mathrm{~nm})$. При комнатной температуре $\mathrm{Mn}$ парамагнетик, с понижением температуры он переходит в антиферромагнитную фазу. Температура Нееля $95 \mathrm{~K}$.

Будучи примесью в полупроводниках $\mathrm{A}_{3} \mathrm{~B}_{5}$ и $\mathrm{A}_{2} \mathrm{~B}_{6}$, легированных марганцем (полумагнитные полупроводники), марганец, как правило, способствует формированию ферромагнетизма в данных кристаллах. Однако в этом случае атомы марганца находятся в разбавленном состоянии и индивидуально связываются со структурами конкретного полупроводника. В ряде работ авторы приходят к заключению, что ферромагнетизм в этом случае обусловлен образованием магнитного полярона.

В порах НПУ марганец может образовывать нанокластеры в углеродном окружении, и в зависимости от их формы и размера поверхность соприкосновения металла и углерода может существенно меняться, что влияет на адсорбционное взаимодействие компонентов. Однако о механизме такого адсорбционного взаимодействия и его эффективности в настоящее время ничего не известно.

Для введения кластеров марганца использовались объемные образцы НПУ в виде пластин толщиной $1 \mathrm{~mm}$, приготовленные из порошка $\mathrm{SiC}(\mathrm{C}(\mathrm{SiC}))$, скрепленного пироуглеродом при отжиге в метане. Далее они были допированы кремнием для реакции с пироуглеродом (и образования $\mathrm{SiC}$ ), после чего образцы были прохлорированы при $1000^{\circ} \mathrm{C}$ для удаления атомов кремния как из первоначальной фазы $\mathrm{SiC}$, так и из вновь образованной. Общая пористость образцов $P=66 \%$, нанопористость $n P=0.44 \mathrm{~cm}^{3} / \mathrm{cm}^{3}$. Средний размер нанопор $\sim 0.8 \mathrm{~nm}$.

Следует заметить, что в литературе отсутствует описание технологии введения металлического марганца в нанопористые углеродные системы. В настоящей работе использована известная реакция восстановления металла $(\mathrm{Mn})$ из двуокиси $\left(\mathrm{MnO}_{2}\right)$ при высокой температуре в смеси с углеродом

$$
\mathrm{MnO}_{2}+2 \mathrm{C}=\mathrm{Mn}+2 \mathrm{CO} .
$$

Естественно, необходимо первоначально ввести $\mathrm{MnO}_{2}$ в поры НПУ. Для введения кластеров $\mathrm{MnO}_{2}$ использовалась химическая реакция

$3 \mathrm{MnCl}_{2}+2 \mathrm{KMnO}_{4}+4 \mathrm{KOH}=5 \mathrm{MnO}_{2} \downarrow+6 \mathrm{KCl}+2 \mathrm{H}_{2} \mathrm{O}$.

Сначала образцы $\mathrm{C}(\mathrm{SiC})$ длительно кипятились в водном растворе хлористого марганца, затем после охлаждения раствора до $\sim 60^{\circ} \mathrm{C}$ в него добавлялся перманганат калия и едкий калий. В результате в осадок выпадал оксид марганца. Раствор фильтровался, поверхность углеродных образцов, в объеме которых также осуществлялась указанная реакция (2), очищалась от порошка $\mathrm{MnO}_{2}$, и далее образцы сушились при температуре $60^{\circ} \mathrm{C}$. После сушки образцы подвергались отжигу в атмосфере проточного аргона при температуре $660^{\circ} \mathrm{C}$ в течение $3 \mathrm{~h}$ для осуществления в них реакции (1).

Для проведения рентгеновских измерений образцы были сразу после отжига помещены в плотно закрытую емкость с гексаном, где они не могли окислиться. Но установка образца, настройка луча и само довольно длительное измерение рентгеновской дифракции осуществлялись на воздухе, и, конечно, поверхность образца 


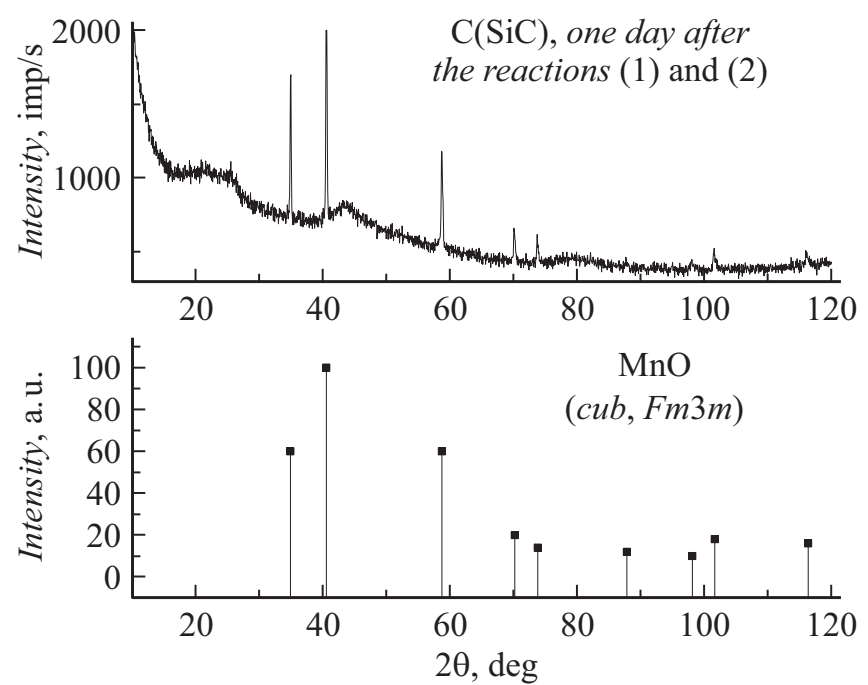

Рис. 1. Рентгенограмма образца $\mathrm{C}(\mathrm{SiC})$ с введенным в него марганцем согласно реакциям (1), (2). Измерения выполнены через 1 день после отжига образца в $\operatorname{Ar}$ (реакция (1)).

могла окислиться в первую очередь. Так оно, видимо, и произошло, поскольку на рентгенограмме (рис. 1) помимо широких пиков, характерных для $\mathrm{C}(\mathrm{SiC})$, наблюдались только узкие пики, соответствующие фазе $\mathrm{MnO}$, присутствующей, по-видимому, на поверхности образца. Узость указанных пиков свидетельствует о достаточно больших размерах формирований $\mathrm{MnO}$ (для сферического приближения $\sim 37 \mathrm{~nm})$. В действительности мы полагаем, что образовались фрагменты тонкой пленки достаточно большой площади. Данные кривые были получены в стандартной геометрии „на отражение“, что благоприятствовало наблюдению поверхностных образований. При этом явных признаков наличия фазы металлического марганца на дифрактограмме зарегистрировано не было. Возможно, это связано с малостью марганцевых фрагментов и вследствие этого очень широкими и малыми по высоте полосами, незаметными на рентгеновской дифрактограмме. Измерения выполнялись на дифрактометре ДРОН-3 (CuK $K_{\alpha}$-излучение), и в этом случае основной пик марганца должен попадать как раз в максимум широкого пика, характерного для НПУ, что также затрудняет его регистрацию. Тем не менее наличие на образце фазы $\mathrm{MnO}$ само по себе свидетельствует о том, что в процессе отжига (реакция (1)) в образце появился Mn. На дифрактограмме также не видно наличия в образце и оксида марганца $\left(\mathrm{MnO}_{2}\right)$. Он должен был войти в микропоры образца из раствора в реакции (2), но размер микропор слишком мал, чтобы образовались нанокристаллиты, которые могли бы наблюдаться в рентгеновской дифракции. Кроме того, при отжиге $\mathrm{MnO}_{2}$ должен преобразовываться в $\mathrm{Mn}$ согласно реакции (1).

Сразу после отжига образцов в $\mathrm{Ar}$ образец, предназначенный для магнитометрии, был помещен в закрытый немагнитный контейнер, который устанавливался в вибрационный магнитометр, и проводилось измерение намагниченности образца (рис. 2). Градуировка этого лабораторного магнитометра осуществлялась путем измерения кривой намагниченности мелких кусочков проволоки из чистого $\mathrm{Ni}$. На рис. 2 приведена зависимость намагниченности образца от поля. Она оказалась линейной и имеющей отрицательный знак, что указывает на диамагнитный характер материала. Следует отметить, что для образцов НПУ вообще характерна большая диамагнитная восприимчивость. Намагниченность и магнитная восприимчивость описываются следующими выражениями:

$$
I=-H \cdot 7 \cdot 10^{-5} \mathrm{emu} / \mathrm{g}, \quad \chi_{\mathrm{DM}}=-70 \cdot 10^{-6} \mathrm{emu} / \mathrm{g} .
$$

Приведенная диамагнитная восприимчивость больше, чем у графита, на порядок. Но существенного влияния обнаруженной на рентгенограмме фазы MnO (парамагнетик) не наблюдалось. Атомы (или кластеры) Mn, которые были введены в нанопоры в объеме углеродного образца, также, по-видимому, слабо повлияли на характер наблюдаемой зависимости сразу после отжига. Либо размер этих кластеров был слишком мал, либо общая концентрация атомов Mn была малой.

Следующее измерение намагниченности этого образца было проведено через 20 дней, причем образец все это время находился в контейнере, установленном в магнитометре.

На рис. 3 показана кривая намагниченности при повторном измерении. Из поведения представленной на рис. 3 зависимости видно, что за 20 дней после первого измерения в магнитных свойствах образца произошли существенные изменения. С увеличением поля кривая становится нелинейной и доходит до насыщения. C уменьшением поля и сменой его знака видно наличие гистерезиса. Образец стал слабо магнитным, скорее всего суперпарамагнитным. Данные результаты

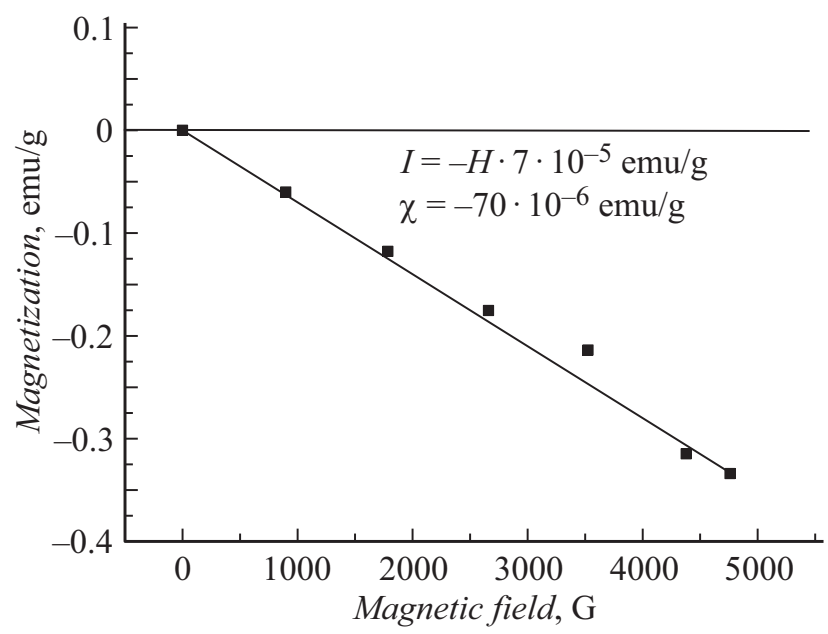

Рис. 2. Зависимость намагниченности образца $\mathrm{C}(\mathrm{SiC}): \mathrm{Mn}$, $\mathrm{MnO}$ от напряженности поля $(T=295 \mathrm{~K})$, измеренная сразу после отжига образца в Ar. 


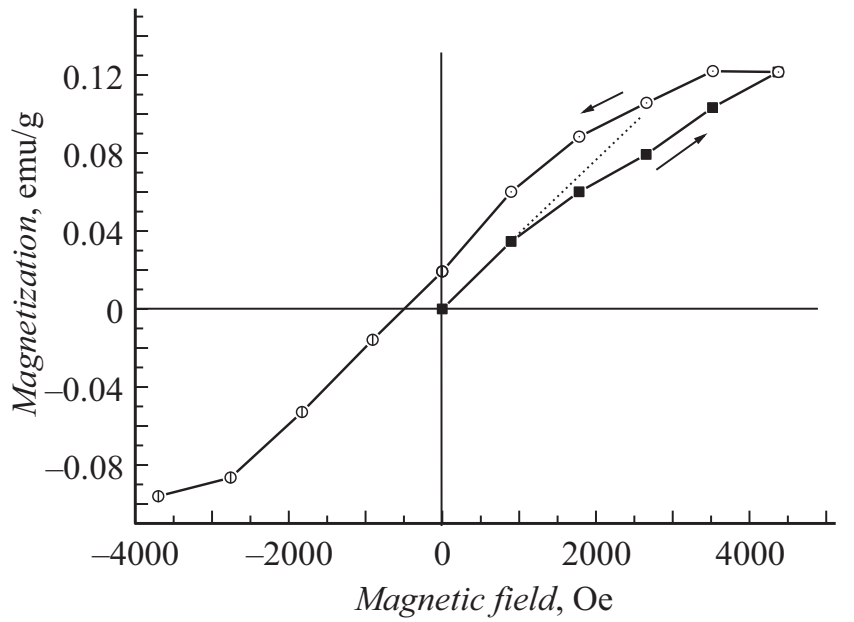

Рис. 3. Кривая намагниченности того же образца через 20 дней. $T=295 \mathrm{~K}$.

качественно повторялись в нескольких контрольных экспериментах.

Поскольку в образце присутствует фаза закиси марганца $(\mathrm{MnO})$, необходимо обсудить возможное влияние указанной фазы на зарегистрированные характеристики намагниченности. Магнитные характеристики $\mathrm{MnO}$ исследовались в ряде работ, например в $[3,4]$. Марганец и его окислы могут находиться в различных структурных состояниях с различным магнитным упорядочением. Как видно из диаграмм, приведенных на рис. 1, в исследованных образцах фрагменты $\mathrm{MnO}$ при комнатной температуре имеют кубическую 3D-симметрию $(F m 3 m)$. В такой фазе они представляют собой диэлектрические парамагнетики с температурой Нееля $119 \mathrm{~K}$ [4], при которой они переходят в антиферромагнитную фазу, и практически при той же температуре в кристаллах возникают структурные искажения. Поскольку приведенные в настоящей работе зависимости намагниченности измерялись при температуре $295 \mathrm{~K}$, наличие $\mathrm{MnO}$ могло повлиять только на значение парамагнитной компоненты намагниченности, но не могло быть причиной возникновения в образцах суперпарамагнетизма. Мы полагаем, что указанный эффект мог быть связан только с наличием и укрупнением со временем кластеров марганца, имеющих адсорбционное взаимодействие с окружающими их углеродными структурами.

Можно предположить, что первоначально очень малые частицы марганца, распределенные в объеме образца, с течением времени благодаря косвенному магнитному взаимодействию путем диффузии объединяются в более крупные фрагменты, которые в окружении атомов углерода способны проявлять суперпарамагнитные свойства. Оценка средних размеров магнитных кластеров исходя из приведенных кривых намагниченности показала, что они не превышают $3 \mathrm{~nm}$.

Альтернативная гипотеза об изменении магнитных свойств образца связана с очень медленным процессом восстановления металлического марганца, продолжающимся и после отжига при комнатной температуре согласно реакции (1), что также приводит к укрупнению кластеров $\mathrm{Mn}$, но она представляется нам менее вероятной. В любом случае полученная зависимость намагниченности (рис. 3) указывает на наличие косвенного $s-d$-обменного взаимодействия $\mathrm{Mn}$ через атомы углерода, которое приводит к слабому магнетизму.

Таким образом, полученный результат подтверждает предположение об адсорбционном взаимодействии электронных термов марганца и углерода, изменяющем электронную плотность на границе раздела, что и обусловливает наблюдаемые магнитные свойства исследованных образцов.

\section{Список литературы}

[1] Данишевский А.М., Макарова Т.В., Ситникова А.А., Шанина Б.Д. // ФТТ. 2011. Т. 53. В. 5. С. 956-963.

[2] Данишевский А.М., Шанина Б.Д., Рогачев А.Ю., Соколов В.В., Калмыков А.Е., Кютт Р.Н., Гордеев С.К. // ФТТ. 2017. T. 59. B. 10. C. 2056-2062.

[3] Pask J.E., Singh D.J., Mazin I.I., Hellberg C.S., Kortus J. // Phys. Rev. B. 2001. V. 64. N 2. P. 024403.

[4] Балагуров А.М., Бобриков И.А., Сумников С.В., Ючанхай В.Ю., Миронова-Улмане Н. // Письма в ЖЭТФ. 2016. T. 104. B. 2. C. $84-90$. 